\title{
Comparative study of the fatigue performance of the micro and nanometric Cr3C2-25NiCr coating sprayed by HVOF on ASTM A516 steel substrate
}

\author{
Rosivania Oliveira ${ }^{1}$, Gabriel Cogo ${ }^{1}$, Brenno Nascimento ${ }^{2}$, Sandro Griza ${ }^{2}$, Antonio Takimi ${ }^{1}$, \\ and Carlos Bergmann ${ }^{1}$ \\ ${ }^{1}$ Universidade Federal do Rio Grande do Sul \\ ${ }^{2}$ Universidade Federal de Sergipe
}

August 4, 2020

\begin{abstract}
$\mathrm{NiCr}$ metal matrix composite reinforced with $\mathrm{Cr} 3 \mathrm{C} 2$ particles can be applied as coating to various pieces of equipment, including those operating under fatigue. In the present study, the nanometric powder was obtained by high energy milling and sprayed by the high velocity oxygen fuel technique on ASTM A516 steel substrate. The comparison was made between the layer obtained from powders in nanometric scale, micrometric scale and mixing $50 \%$ of both. The coating thickness, hardness, microstructure, porosity and roughness were evaluated. Fatigue tests were performed on the three coatings in addition to the layer free substrate. The effect of coating morphology and its roughness on fatigue performance was studied. The surface roughness of the Nano coating was significantly lower than both of the other coatings. However, the three different layers that were tested did not experience significant differences in their fatigue performance. All three coatings had lower fatigue performance than the steel substrate.
\end{abstract}

Article

Comparative study of the fatigue performance of the micro and nanometric $\mathrm{Cr}_{3} \mathrm{C}_{2}-25 \mathrm{NiCr}$ coating sprayed by HVOF on ASTM A516 steel substrate

Rosivânia da Paixão Silva Oliveira ${ }^{1, *}$, Gabriel Rausch Cogo $^{1}$, Brenno Lima Nascimento ${ }^{2}$, Sandro Griza ${ }^{2}$, Antônio Takimi ${ }^{1}$, Carlos Pérez Bergmann ${ }^{1}$

${ }^{1}$ Department of Materials, Federal University of Rio Grande do Sul, Porto Alegre, Rio Grande do Sul.

${ }^{2}$ Center for Technological Development, Federal University of Sergipe, São Cristóvão, Sergipe, Brasil.

* Email: rosipoliveira2020@gmail.com; rosipaixao@yahoo.com.br; Phone: +55 79988143043

Abstract: $\mathrm{NiCr}$ metal matrix composite reinforced with $\mathrm{Cr}_{3} \mathrm{C}_{2}$ particles can be applied as coating to various
pieces of equipment, including those operating under fatigue. In the present study, the nanometric powder
was obtained by high energy milling and sprayed by the high velocity oxygen fuel technique on ASTM A516
steel substrate. The comparison was made between the layer obtained from powders in nanometric scale,
micrometric scale and mixing $50 \%$ of both. The coating thickness, hardness, microstructure, porosity and
roughness were evaluated. Fatigue tests were performed on the three coatings in addition to the layer free
substrate. The effect of coating morphology and its roughness on fatigue performance was studied. The 
surface roughness of the Nano coating was significantly lower than both of the other coatings. However, the three different layers that were tested did not experience significant differences in their fatigue performance. All three coatings had lower fatigue performance than the steel substrate.Keywords: nanometric coating, $\mathrm{HVOF}$, fatigue, $\mathrm{Cr}_{3} \mathrm{C}_{2}-25 \mathrm{NiCr}$ coating.

\section{Introduction}

Protective coating can increase the life of piping, vessels, and several other equipment and structures, as the coating protects the substrate against corrosion and wear mechanisms $[1,2,3]$. Damage mechanisms such as fatigue, high temperature oxidation [3], wear [4] pose a risk to the equipment surface quality. Thus, surface modification techniques are implemented to provide coatings on the surface of the base material [5].

Fatigue failure is important in components and structures, because when the crack that nucleates and propagates reaches its critical size, it can lead the component to a catastrophic rupture.[6 - 8]. The roughness of the surface that is subjected to positive stresses in the fatigue loading is an important parameter, since fatigue nucleation is dependent on the stress raisers attributed to the surface roughness. In addition, residual stresses have been considered a critical factor for the fatigue behavior [9]. The fatigue performance is improved by surface compressive stresses which hinder crack nucleation, as these compressive stresses will be an additive to external stresses for determining the effective stress acting on the component [10]. One of the great benefits of coatings is to promote compressive residual stresses on the surface [6]. Some parameters such as torch operating parameters, feedstock characteristics, deposition rates and differences in the coating and substrate's thermal expansion coefficient have all demonstrated great influence in coating stresses [9]. Furthermore, coating's microstructures with higher toughness lead to delayed crack nucleation [6].

Metal matrix composites and dispersed carbide microparticles are common in the surface coating in industrial practice. Currently, the deposition of nickel-chromium ( $\mathrm{NiCr}$ ) alloy has been the subject of increased attention. The $\mathrm{NiCr}$ alloy as a metal matrix gives toughness to the layer, as well as corrosion and oxidation resistance. Chromium carbides particles $\left(\mathrm{Cr}_{3} \mathrm{C}_{2}\right)$ are well known and widely used for wear protection purposes [11], as these particles can increase the mechanical strength of the layer and act against erosive and abrasive wear [2]. The $\mathrm{Cr}_{3} \mathrm{C}_{2}$ has high strength properties, high coating adhesion, low density and good chemical stability [11].

Nanostructured coatings can undergo potentialities in their physical and mechanical properties, such as mechanical strength, hardness, ductility, specific heat, diffusivity [12]. Coatings obtained from milled powders down to the nanometer level, whose structure contains nanometric crystallites, provide coating with greater adhesion to the substrate, significantly lower porosity and higher surface quality, lower roughness, in addition to the increased hardness and wear resistance [11]. The high energy milling (HEM) is a technique where powder mixtures of different metals are ground together to obtain a homogeneous alloy [13]. This process causes intense plastic strain of the powders, leading the particles to hardening, fracture and subsequent cold welding in successive stages [14]. The structure of the particles is continuously refined due to the energy transferred by the continuous impact of the grinding bodies. The structure undergoes intense multiplication of dislocations, which leads to the reduction of its long-range order, promoting particles fracture up to the nanometer scale, although they remain as crystallites. The HEM allows nanostructured materials to be synthesized easily in a short time [13]. Moreover, the main objectives of the HEM for the synthesis of $\mathrm{Cr}_{3} \mathrm{C}_{2}-25 \mathrm{NiCr}$ coating powder are: i) to reduce the granulometry of the composite; ii) to ensure that the carbide particles will be surrounded by the precursor constituent of the $\mathrm{NiCr}$ binder phase; iii) to create new active surfaces and structural defects in the composite [15]. Reducing the particle size of the powder causes an increase in the grain boundary area of the layer splats, which increases the hardness of the layer due to the restriction of dislocations [15].

The coating method may also be an important factor for the resulting properties of the layer. The high velocity oxygen fuel (HVOF) is a thermal spraying technique, widely used for coating's manufacture $[8,15-$ 20]. The hypersonic flame at speeds of up to $3000 \mathrm{~m} / \mathrm{s}$ releases large energy that is converted into heat and pressure. The particles reach the substrate forming a dense and hard coating, with extremely low porosity 
and high adhesion strength, retaining nanometric crystallites after deposition [21], resulting in dense, hard [22], fatigue strength [8] and well bonded coatings [9, 22]. Nanostructured material sprayed by HVOF makes the coating more resistant to crack propagation [12]. Although conventional thermal spraying causes particles to melt, high temperature and high-speed spraying cause plastic strain of the powder upon impact with the substrate, forming mechanically bonded splats that cool at a rate of up to $1 \times 10^{6} \mathrm{~K} / \mathrm{s}$ [4]. The accumulation of large number of splats gives rise to the coating building. The rapid solidification of the $\mathrm{Cr}_{3} \mathrm{C}_{2}-25 \mathrm{NiCr}$ particles can leads to the formation of an amorphous / nanocrystalline nickel supersaturated in chromium binder phase, besides retaining the $\mathrm{Cr}_{3} \mathrm{C}_{2}$ and $\mathrm{NiCr}$ phases $[2-5,13-15]$.

The strong mechanical bond between splat and substrate impedes the relative sliding of splat $[8,11,15,23]$. Thus, fatigue cracks arising from the coating surface would cause increased stresses at the interface with the substrate, favoring the crack propagation into the substrate. Since the concentrated stress is greater than the applied stress, it reduces the fatigue limit [23].

The size of sprayed powders intimately effects the physical and mechanical properties of the coating. Structure formed by nanometer crystallites of the coating and high volumetric fraction of atoms in the layer's grain boundaries can improve mechanical properties [13]. Coatings obtained from nanometric powders have been researched more recently, and their use enhances coating performance gains [1, 10, 22, 24]. Studies show that coatings increase wear resistance over the substrate $[10,18,25-26]$. However, concern about the fatigue performance of coatings is important in the case of equipment operating under cyclical stresses. Therefore, it is important to evaluate the fatigue strength of the coating obtained from nanometric powder and combinations of this with micrometric powder to determine whether there is advantage in expending high energy milling effort on this fatigue strength property.

The present study evaluates the fatigue performance of the coatings given by particles of $\mathrm{Cr}_{3} \mathrm{C}_{2}$ and $\mathrm{NiCr}$, both in nanometric scale, micrometric scale and a combination of $50 \%$ of both, sprayed by the HVOF technique on ASTM A516 steel substrate.

\section{Materials and Methods}

The commercially manufactured micrometric $\mathrm{Cr}_{3} \mathrm{C}_{2}-25 \mathrm{NiCr}$ powder (PRAXAIR Surface Technologies) containing 75 wt $\%$ of $\mathrm{Cr}_{3} \mathrm{C}_{2}, 20 \%$ of $\mathrm{Ni}$ and $5 \%$ of $\mathrm{Cr}$ was used in the present study [27].

Pulverisette 6 planetary grinding mill equipped with steel-coated grinding jar and $5 \mathrm{~mm}$ zirconium oxide spheres of grinding bodies allowed to evaluate the HEM method, to give the nanometric powder. The mass ratio of the spheres and raw material were 5:1. The milling speed was $800 \mathrm{rpm} .20 \mathrm{ml}$ of ethyl alcohol and $3 \%$ of alumina was added as a milling medium, to increase the grinding efficiency, inhibiting the particle's growth, controlling the grain size and avoiding the agglomeration of nanometric particles [28]. The powder was ground up for 12 hours. Them, it was dried in an oven at $50^{\circ} \mathrm{C}$ for 20 minutes and finally sieved on 325 Mesh, according to a recommended protocol [15].

Laser diffraction granulometer with detection range of 0.04 to $2500 \mu \mathrm{m}$ (CILAS - 1180) provided the particle size analysis. Samples with $10 \mathrm{mg}$ of powder were dispersed in water and it was subjected to ultrasonic agitation for 60 seconds for deagglomeration prior to the analysis.

X-ray diffraction (XRD) analysis enabled the phases characterization, using the Philips X-Ray Analytical Equipment X'Pert-MPD System, console PW3040/00 and PW3373/00, anode CuK $\alpha$. Parameters used were $40 \mathrm{kV}$ and $40 \mathrm{~mA}, 10 \mathrm{~mm}$ window, $1^{\mathrm{O}}$ slot, angle between $5^{0}$ and $75^{\mathrm{o}}$. The diffractograms were treated and analyzed through the software WinFit 1.2, employing the Single - Line method to calculate the mean diameter of the crystallites [13]. Scanning electron microscope (SEM JOEL Carry Scope JSM-5700) and energy dispersive spectroscopy (EDS) techniques were applied for the powders and coating analysis.

Three different layers were established: 1 ) coating obtained from the nanometric powder (Nano); 2) coating obtained from micrometric powder (Micro) and 3) coating containing $50 \mathrm{wt} \%$ of both powder's granulometry (NM). The specimens of ASTM A516 steel $(75 \times 15 \times 5 \mathrm{~mm})$ were machined and alumina blasting was carried out over one face of each specimen to enhance the coating anchoring. The coating equipment used was the 
TAFA JP 5000 HP/HVOF System 5120, PRAXAIR and TAFA GUN 5220 pistol. To reduce the analysis variables, it was attempted to evaluate the coatings by fixing factors such as thickness and porosity and parameters for HVOF spraying are optimized and listed in Table 1.

Table 1. HVOF spraying parameters of the $\mathrm{Cr}_{3} \mathrm{C}_{2}-25 \mathrm{NiCr}$ coating.

\begin{tabular}{ll}
\hline Flow rate of propane $\left(\mathrm{GPH}^{\mathrm{a}}\right)$ & 5,1 \\
\hline Flow rate of oxygen $\left(\mathrm{SCFH}^{\mathrm{b}}\right)$ & 2054 \\
Feeding rate $(\mathrm{g} / \mathrm{min})$ & 40 \\
Spray distance $(\mathrm{mm})$ & 220 \\
Number of passes & 01 \\
Spray angle $(\stackrel{\mathrm{o}}{ })$ & 90 \\
\hline
\end{tabular}

a $1 \mathrm{GPH}=3,785 \mathrm{~L} / \mathrm{h}^{\mathrm{b}} 1 \mathrm{SCFH}=0,472 \mathrm{~L} / \mathrm{min}$

Metallographic samples were prepared for the measurement of the coating's thickness, porosity and microhardness, as well as to the microstructure analysis. The samples were sanded up to 2000 Mesh and polished through $1 \mu \mathrm{m}$ diamond paste. Nital $2 \%$ was applied as etching reagent. Three metallographic samples of each coating were prepared. For each sample, 6 images were obtained at different sites of the coating, which were treated by the Axiovision program to the porosity analysis. The Buehler Micromet 2001 microhardness tester allowed to perform the Knoop microhardness (HK) on the coatings. The Knoop scale was chosen to ensure adequate microhardness measurement on the thin layers produced. Five indentations for each sample were performed, applying load of $0.05 \mathrm{kgf}$ [29]. An optical microscope (Zeiss 1500LCD) and stereomicroscope (Zeiss Stemi 2000C) also were used to coatings analysis.

The thresholding method are used for porosity analysis, when the amplitudes of the gray levels are sufficient to characterization [30]. The Images were obtained through the optical microscope. In the program used in digital imaging processing, segmentation of objects (group of pixels) takes place. Darker shades, in this case, meaning voids between fused particles.

The roughness $(\mathrm{Ra})$ were evaluated longitudinally in 5 specimens after spraying. The Mitutoyo Roughness SJ-410 was used at velocity of $0.2 \mathrm{~mm} / \mathrm{s}$ and at $2.5 \mathrm{~mm}$ median line, obtaining 10 measurements for each specimen.

The 3 points bending fatigue test was performed using the MTS Landmark 370.02, to give the SN curve in 17 specimens of each coating as well as the substrate. The parameters applied were $30 \mathrm{~Hz}$ frequency, loading ratio $\mathrm{R}=0.1$, cylinders of $5 \mathrm{~mm}$ diameter as supports and plunger, and spam of $30 \mathrm{~mm}$. The staircase method, according to BS ISO 12107 standard, was conducted to give the endurance limit. The first stress level matching the first level of non-failure event up to $5 \times 10^{6}$ cycles is given. The tests proceed by decreasing or increasing the stress level by the standard deviation of the fatigue strength if the preceding event is failure or non-failure, respectively. The S-N curve was achieved for each group studied.

The analysis of variance ONE WAY ANOVA (p [?] 0.05) allowed to determine statistical differences between groups in regard to thickness, porosity, hardness, roughness and endurance limit.

\section{Results and Discussions}

Figure 1 shows the particles diameter as a function of the HEM time. The microscopic powder mean diameter is $45 \mu \mathrm{m}$ [27]. The first two hours of milling promotes a drastic reduction of the particle's diameter, tending to saturation after 5 hours. The HEM promotes diameter reduction to $13 \mathrm{~nm}$ after 12 hours of milling. Therefore, it can be assumed that the nanometric powder may consist of amorphous structures and crystal dispersions.

Figure 1. Particles diameter as a function of HEM time. A sudden drop of the diameter before 5 hours of milling is observe 
The XRD analysis (Figure 2 ) explains the presence of $\mathrm{Cr}_{3} \mathrm{C}_{2}$ [13, 15, 20, 27, 29], and $\mathrm{Cr}_{7} \mathrm{C}_{3}$ in the micrometric powder. The intensity of the peaks decreases, while they expand as a function of milling time. The increase in the width of the XRD peaks with the grinding time is attributed to the decrease in the carbide structure that forms small grains. Moreover, the peaks of the $\mathrm{Cr}_{3} \mathrm{C}_{2}$ persist after 12 hours of HEM, indicating preservation of some extent of the crystalline structure. The $\mathrm{Cr}_{7} \mathrm{C}_{3}$ content decreases with the HEM time, which can be explained by the atom's rearrangement due the high strain energy. Furthermore, the $\mathrm{Cr}_{2} \mathrm{O}_{3}$ peak emerges with the HEM time increase, which could be explained by the increased amount of the $\mathrm{Cr}_{2} \mathrm{O}_{3}$ protective film surrounding the increased amount of nanoparticle free surfaces, as the particle's diameter decrease. Ni XRD analysis was not performed because the major concern was with carbide, as it is harder and has a higher melting point, which makes it more difficult to deform when HEM process is performed.

$\overline{\text { Figure 2. XRD analysis of the } \mathrm{Cr}_{3} \mathrm{C}_{2}-25 \mathrm{NiCr} \text { powder as a function of milling time. }}$

Figure 3 explains the morphology and distribution in each of the three constituent powders. The granulometry difference is highlighted in the images, as well as the distribution of nanometric particles around the micrometric agglomerations that occurs in the mixture of NM powders. Figure 3 also shows EDS analysis representative to the NM composition. Beyond those expected elements constituents of the powder, $\mathrm{Zr}$ and $\mathrm{Al}$ are detected in the HEM processed powders, but in higher content for the Nano powder. The contamination comes from the $\mathrm{Zr}$ grinding bodies and the alumina addition during the HEM process. It is a limiting factor of the HEM process with respect to the degree of purity of the coatings.

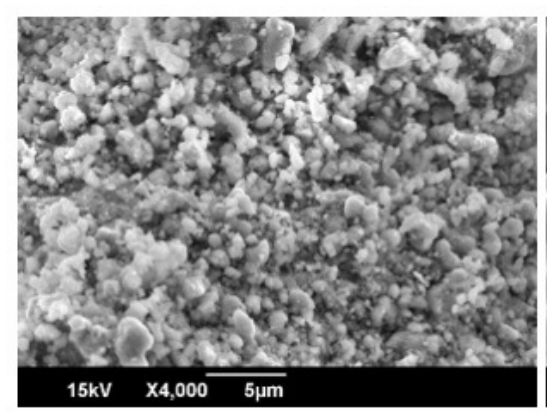

(a)

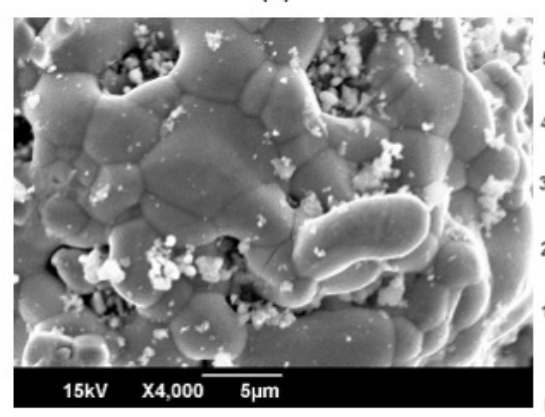

(c)

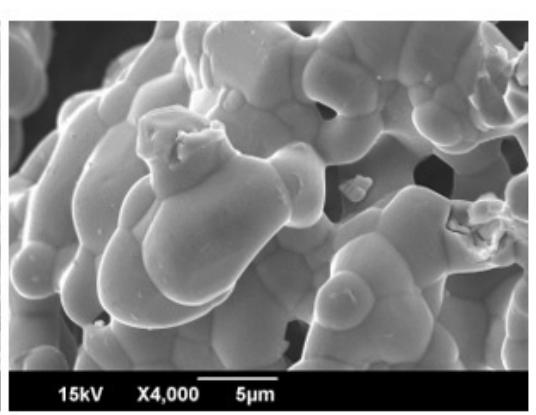

(b)

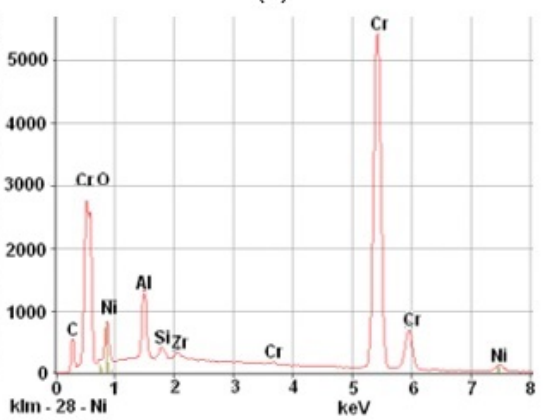

(d)

Figure 3. SEM images of the three $\mathrm{Cr}_{3} \mathrm{C}_{2}-25 \mathrm{NiCr}$ powders. (a) Nano, (b) Micro, (c) NM. EDS analysis of the NM powder shows $\mathrm{Zr}$ and $\mathrm{Al}$ contaminants (d).

It is possible to differentiate the $\mathrm{NiCr}$ from carbide particles through EDS mapping, although there is no variation in particle morphology, even with different compositions, as can be explained from the SEM 
analysis. Figure 4 shows EDS mapping of the Micro powder, highlighting a Ni rich metallic particle with the same morphology of the $\mathrm{Cr}_{3} \mathrm{C}_{2}$.

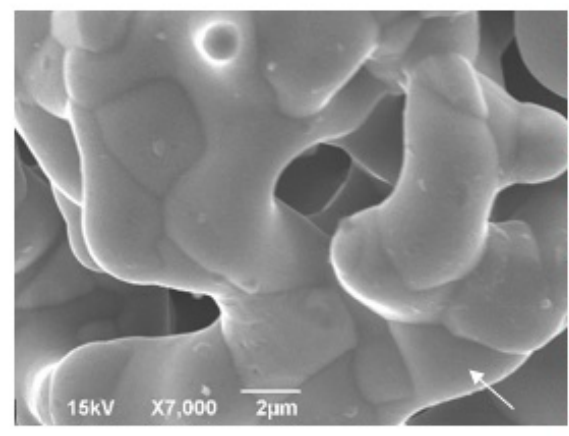

(a)

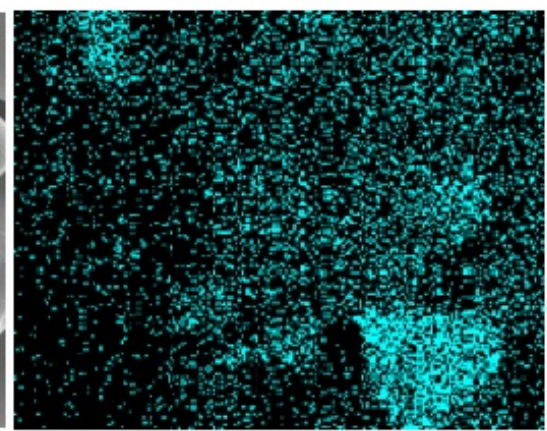

(b)

Figure 4. The arrow indicates a Ni rich particle in the SEM image (a), which was identified by the EDS mapping (b).

Figure 5 is a representative optical image demonstrating the formation of ferrite and perlite microstructure of the steel substrate and the coating thickness irregularity. Alumina was identified by EDS analysis adhered to the substrate due to the blasting, and it appears as the dark grey phase on the optical microscopy. There is no good resolution of coating splats in optical microscopy.

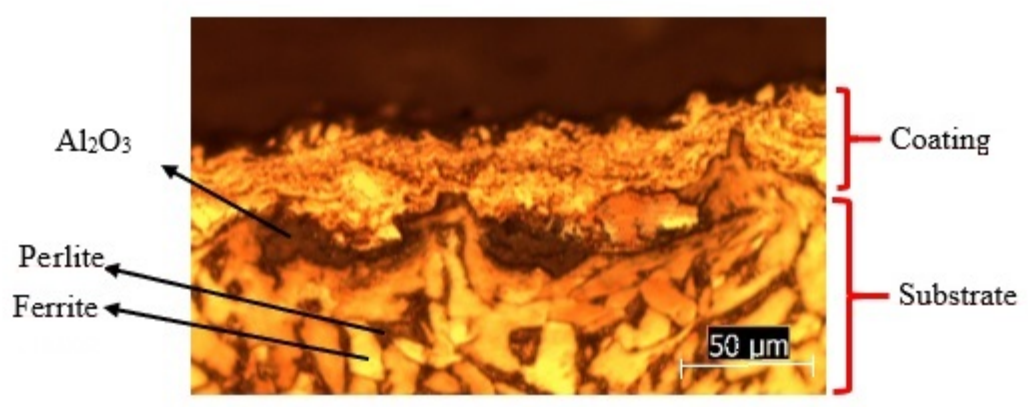

Figure 5. Representative optical microscopy of the Nano coated on the ferrite and perlite substrate. Dark grey phases are alumina adhered on the substrate after blasting.

Figure 6 shows the SEM image of the Micro coating and the EDS mapping of the Cr. The images allow us to understand that the lightest gray phase of the layer observed in the SEM refers to the NiCr metal, while the darkest phase is $\mathrm{Cr}_{3} \mathrm{C}_{2}$ rich in Cr. Thus, the images allow us to observe the architecture of the layer with the morphology of the splats of different natures. 


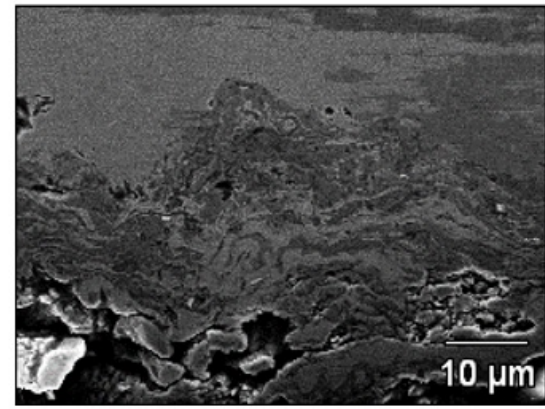

(a)

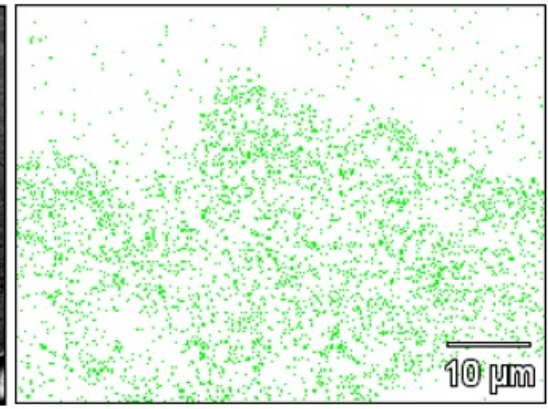

(b)

Figure 6. (a) SEM image of Micro coating and (b) EDS mapping searching for Cr element. Dark gray phases are $\mathrm{Cr}$ rich $\mathrm{Cr}_{3} \mathrm{C}_{2}$ splats, while light gray phases are $\mathrm{NiCr}$ splats.

Figure 7 gives representative images of Nano and Micro coatings. The sprayed powder builds up a laminar architecture of flat, scattered particles (splats). The size of the splats is according to the size of the powder. The Nano coating microstructure is more refined, therefore containing the higher amount of splat boundaries. Alumina can be seen closer to the interface between the coating and substrate. The alumina is undesirable because it can negatively affect the adhesion of the coating and because it can be a stress riser for fatigue.

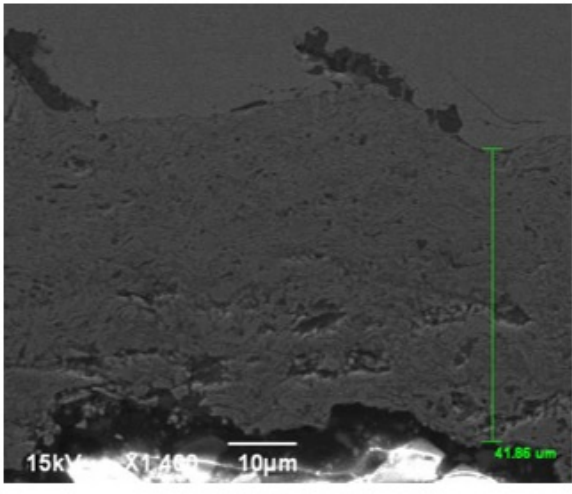

(a)

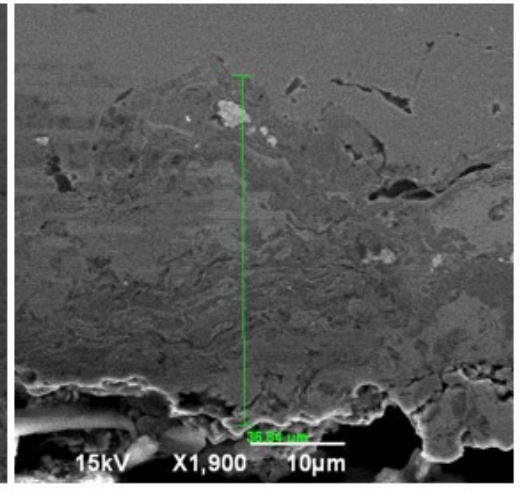

(b)

Figure 7. SEM images showing features of the coating's microstructure. (a) Nano, (b) Micro. Thickness measurements can be seen.

Hardness, thickness and porosity were statistically the same for the Nano, Micro and NM coatings, as shown in Table 2.

Table 2. Analysis of the coating's microstructure Nano, Micro e NM. Standard deviations are in parenthesis.

\begin{tabular}{llll}
\hline Feature & Coating & Coating & Coating \\
\hline & Nano & Micro & NM \\
Hardness & $1.166 \mathrm{HK}(189 \mathrm{HK})$ & $1.081 \mathrm{HK}$ & $1.177 \mathrm{HK}(232 \mathrm{HK})$ \\
Thickness & $42 \mu \mathrm{m}(9 \mu \mathrm{m})$ & $40 \mu \mathrm{m}(8 \mu \mathrm{m})$ & $50 \mu \mathrm{m}(5 \mu \mathrm{m})$ \\
Porosity & Below $2 \%$ & Below $2 \%$ & Below $2 \%$
\end{tabular}




\begin{tabular}{llll}
\hline Feature & Coating & Coating & Coating \\
\hline Roughness & $1,270 \mu \mathrm{m}(0,028 \mu \mathrm{m})$ & $1,410 \mu \mathrm{m}(0,048 \mu \mathrm{m})$ & $1,579 \mu \mathrm{m}(0,039 \mu \mathrm{m})$ \\
\hline
\end{tabular}

The roughness is affected significantly by the type of coating. The coated surface of a given item of equipment is usually machined after coating to reduce its roughness. In our study instead, machining was not carried out to study what could be the worst case scenario of a given surface of difficult access, and to analyze the possible effect of roughness of coated layer.

The lowest roughness of the Nano coating would be a consequence of the finer splat's architecture. The NM coating presented the highest roughness. It can be explained by the particle's accommodation. Particle's packing is defined by filling the voids between larger particles with smaller ones, whose voids will be filled again with even smaller particles and so on. However, the Nano particles agglomerates itself, as could be seen in the powder analysis, and do not fill so well the voids between the Micro particles. It hinders the proper packaging, which reflects in the roughness of the layer.

The fatigue nucleation is encouraged by the roughness increase [18]. The fatigue strengths of the three coatings are comparable to each other, although they are lower than the substrate (Figure 8). The fatigue limits found for layers Nano, NM and Micro were, respectively, $302 \mathrm{MPa}, 297 \mathrm{MPa}$ and $311 \mathrm{MPa}$. Taking the standard deviation of $25 \mathrm{MPa}$ stipulated by the applied method, there is no significant difference between the fatigue limits of the three coatings. The substrate fatigue limit of $400 \mathrm{MPa}$ exceeds those of all the coatings. Factors attributed to the critical stress for fatigue nucleation, positive residual stresses and roughness, can adversely affect the coatings fatigue performance.

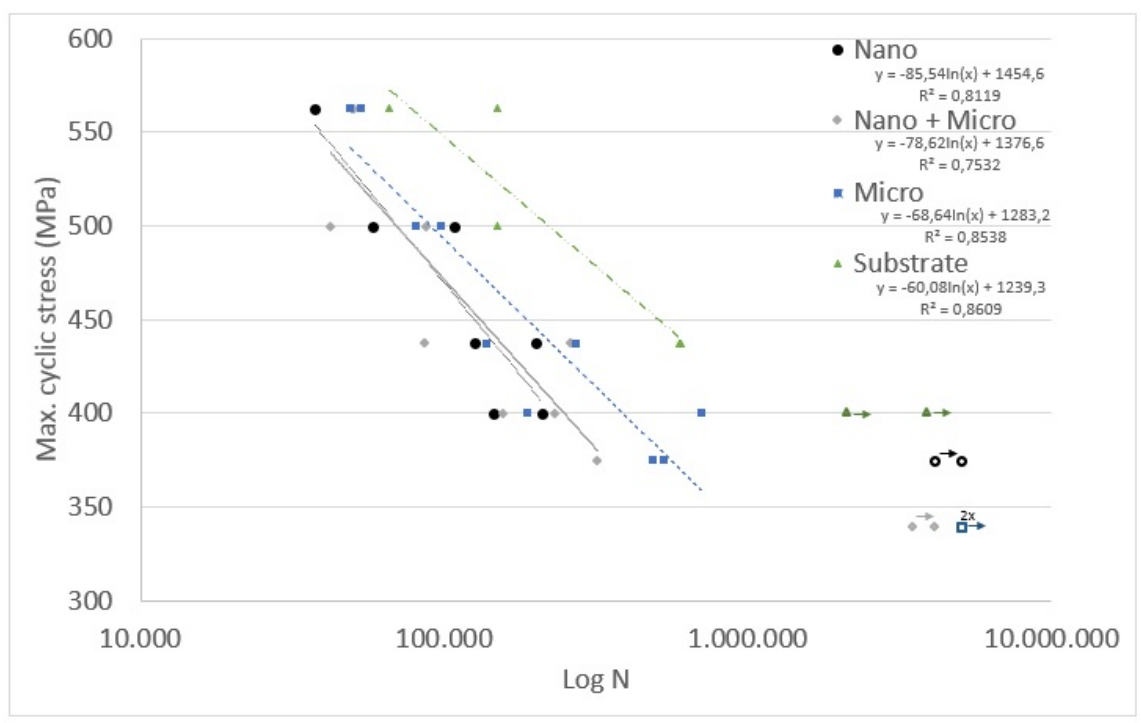

Figure 8. SN curves of the Nano, Micro, NM and Substrate. The open dots represent specimens that did not fracture during the test.

Some studies which tested thicker coatings denoted better fatigue performance of the coatings compared to the substrate $[7-9,12,23]$. However, our study aimed to comparatively evaluate the selected coatings. Therefore, the study allowed to observe that the coatings performed equally in fatigue, regardless of the powder's granulometry. Fatigue performance can be enhanced by some means which provide substantial compressive residual stresses of the coated material, that hinder crack initiation [1]. The residual stresses induced on the surface by the HVOF deposition process are usually positive, but in some cases the stresses can be compressive, especially in metal-ceramic composites, as is our case. 
Figure 9 gives representative images of all the coating specimens fractured during the tests. Striations evidence that the fatigue nucleates at the coating surface.

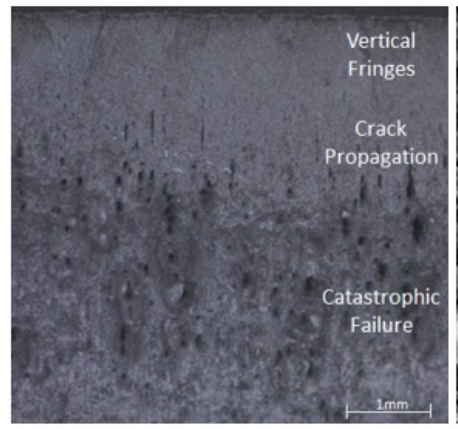

(a)

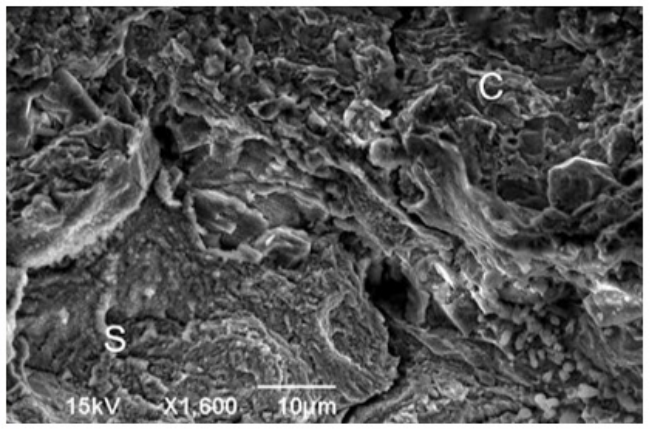

(b)

Figure 9. (a) Image that represents all the coating specimens fractured during the tests; (b) SEM image of the interface between coating (C), top of figure, and substrate (S) showing striations in both sides. Sample Nano.

Secondary cracks (Figure 10) on the side of the specimen which undergoes positive fatigue stress agree with this finding. Critical stresses for fatigue nucleation were more easily approached at the coatings than the substrate. This may be because the elastic modulus of the layer is larger than the substrate, making it less prone to elastic straining the layer without crack formation. Therefore, several nucleation sites emerged early on the layer's surface, before that the fatigue cycles were enough to nucleate the fatigue in the substrate. The reduction of the cycles for fatigue nucleation in the coatings leads, finally, to their lower fatigue performance as compared to the substrate. When the crack hits the substrate, however, it progresses in only one plane. The reduction of the cycles for fatigue nucleation in the coatings leads, finally, to their lower fatigue performance as compared to the substrate. It also shows that the reduction in fatigue resistance is associated with easier nucleation of fatigue in the layers than in the substrate.

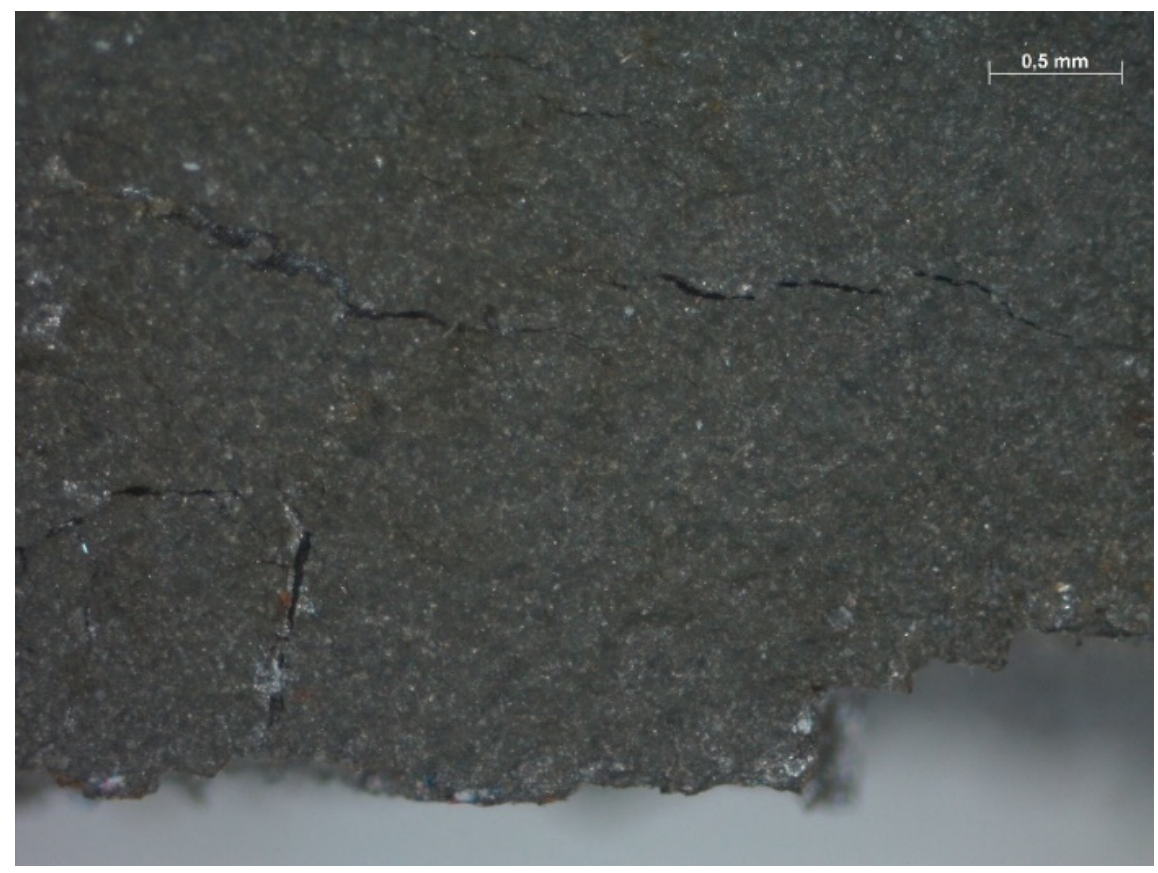


Figure 10. Stereomicroscopy showing the secondary cracks on the coating surface, closer to the fracture plane, after fatigue fracture.

\section{Conclusion}

The present study evaluates the fatigue performance of the coatings given by particles of $\mathrm{Cr}_{3} \mathrm{C}_{2}$ and $\mathrm{NiCr}$, both in nanometric scale, micrometric scale and a combination of $50 \%$ of both, sprayed by the HVOF technique on ASTM A516 steel substrate. The study allows the following conclusions:

- The surface roughness of the Nano coating was significantly lower than both the other coatings. However, the three different layers tested did not experience significant differences in their fatigue performance.

- The layers deposition parameters promoted layers whose fatigue performance does not overcome the fatigue performance of uncoated substrate.

- HEM method allowed $\mathrm{Cr}_{3} \mathrm{C}_{2}-25 \mathrm{NiCr}$ powder to reach the nanometric size, tending to saturation of 15 nm after 5 hours of milling.

- The microstructural refinement of the splats is in accordance to the size of the particles spraying. The Nano coating shows more refined microstructure.

- The layer's thickness, hardness and porosity did not present significant differences in relation to the type of coating.

\section{Acknowledgements}

The authors would like to thank the financial support of FINEP and the Rijeza Metallurgical Industry for technical support and HVOF depositions.

\section{References}

[1] T. Peat, A. M. Galloway, A. I. Toumpis, and D. Harvey, "Evaluation of the synergistic erosion-corrosion behaviour of HVOF thermal spray coatings," Surface Coatings Technology, vol. 299, pp. 37-48, 2016.

[2] J. A. Picas, A. Forn, A. Igartua, and G. Mendoza, "Mechanical and tribological properties of high velocity oxy-fuel thermal sprayed nanocrystalline $\mathrm{CrC}$ - NiCr coatings," vol. 175, no. 03, pp. 1095-1100, 2003.

[3] T. Varis, T. Suhonen, O. Calonius, J. Cuban, and M. Pietola, "Optimization of $\mathrm{HVOF} \mathrm{Cr}_{3} \mathrm{C}_{2}-\mathrm{NiCr}$ Coating for Increased Fatigue Performance," Surface Coatings Technology, vol. 305, pp. 123-131, 2016.

[4] S. Matthews and L. Berger, "Long-term Compositional / Microstructural Development of $\mathrm{Cr}_{3} \mathrm{C}_{2}-\mathrm{NiCr}$ Coatings at $500^{\circ} \mathrm{C}, 700^{\circ} \mathrm{C}$ and $900^{\circ} \mathrm{C}$," Int . J. Refract. Met. Hard Mater. , vol. 59, pp. 1-18, 2016.

[5] B. Somasundaram, R. Kadoli, and M. R. Ramesh, "Evaluation of Thermocyclic Oxidation Behavior of HVOF Sprayed $\left(\mathrm{Cr}_{3} \mathrm{C}_{2}-35 \% \mathrm{NiCr}\right)+5 \%$ Si Coatings on Boiler Tube Steels," Procedia Mater. Sci. , vol. 5 , pp. 398-407, 2014.

[6] S. Singh, H. S. Sidhu, and B. S. Sidhu, "Characterisation and Corrosion-Erosion Behaviour of Carbide based Thermal Spray Coatings," vol. 11, no. 6, pp. 569-586, 2012.

[7] R. T. R. McGrann, D. J. Greving, J. R. Shadley, El F. Rybicki, T. L. Kruecke, B. E. Bodger, "The effect of coating residual stress on the fatigue life of thermal spray-coated steel and aluminum",Surface Coatings Technology , 108-109, pp. $59-64,1998$.

[8] A. Ibrahim, C. C. Berndt, "Fatigue and deformation of HVOF sprayed WC-Co coatings and hard chrome plating", Materials Science and Engineering, vol. 456, pp. 114 - 119, 2007.

[9] A. Vackel, S. Sampath, "Fatigue behavior of thermal sprayed WC-CoCr-steel systems: Role of process and deposition parameters",Surface Coatings Technology, vol. 315, pp. 408 - 416, 2017.

[10] F. Zishuan, W. Shansong, and Z. Zhengdong, "Microstructures and Properties of Nano-structural WC12Co Coatings Deposited by AC-HVAF," Rare Met. Mater. Eng., vol. 46, no. 4, pp. 923-927, 2017. 
[11] F. Zishuan, W. Shansong, and Z. Zhengdong, "Microstructures and Properties of Nano-structural WC12Co Coatings Deposited by AC-HVAF," Rare Met. Mater. Eng. , vol. 46, no. 4, pp. 923-927, 2017.

[12] A. Ibrahim, R. S. Lima, C. C. Berndt, B. R. Marple, "Fatigue and mechanical properties of nanostructured and conventional titania $\left(\mathrm{TiO}_{2}\right)$ thermal spray coatings", Surface Coatings Technology, vol. 201, pp. $7589-7596,2007$.

[13] W. C. Guaglianoni, A. S. Takimi, J. Vicenzi, and C. P. Bergmann, "Synthesis of WC-12wt\%Co Nanocomposites by High Energy Ball Milling and Their Morphological Characterization," Tecnol. em Metal. Mater. e Mineração , vol. 12, pp. 211-215, 2015.

[14] N. A. N. Balbino, L. de C. Valeriano, E. O. Correa, and J. N. Santos, "Microstructural Characterization of the Powder and the Cemented Carbide WC-8Ni-2Mo2C," 23rd ABCM Int. Congr. Mech. Eng., vol. 1, pp. 1-8, 2015.

[15] W. Chen, T. Mao, B. Zhang, S. Zhang, and X. Meng, "Designs and Preparation of Advanced HVOFPVD Duplex Coating by Combination of HVOF and Arc Ion Plating," Surf. Coatings Technol., vol. 304, pp. 125-133, 2016.

[16] D. Jin, F. Yang, Z. Zou, L. Gu, X. Zhao, F. Guo, and P. Xiao, "A Study of the Zirconium Alloy Protection by $\mathrm{Cr}_{3} \mathrm{C}_{2}-\mathrm{NiCr}$ Coating for Nuclear Reactor Application," Surf. Coatings Technol. , vol. 287, pp. 55-60, 2016.

[17] E. Mayrhofer, L. Janka, W. P. Mayr, J. Norpoth, M. Rodriguez Ripoll, and M. Gröschl, "Cracking resistance of $\mathrm{Cr}_{3} \mathrm{C}_{2}-\mathrm{NiCr}$ and $\mathrm{WC}-\mathrm{Cr}_{3} \mathrm{C}_{2}-\mathrm{Ni}$ thermally sprayed coatings under tensile bending stress," Surf. Coatings Technol., vol. 281, pp. 169-175, 2015.

[18] T. Varis, T. Suhonen, O. Calonius, J. Čuban, and M. Pietola, "Optimization of $\mathrm{HVOF} \mathrm{Cr}_{3} \mathrm{C}_{2} \mathrm{NiCr}$ coating for increased fatigue performance," Surf. Coatings Technol. , vol. 305, pp. 123-131, 2016.

[19] D. Verdi, M. A. Garrido, C. J. Múnez, and P. Poza, " $\mathrm{Cr}_{3} \mathrm{C}_{2}$ Incorporation Into an Inconel 625 Laser Cladded Coating: Effects on Matrix Microstructure, Mechanical Properties and Local Scratch Resistance," Mater. Des. , vol. 67, pp. 20-27, 2015.

[20] C. A. da Cunha, O. V. Correa, I. J. Sayeg, and L. V. Ramanathan, "High Temperature Erosion-oxidation Resistance of Thermally Sprayed Nanostructured $\mathrm{Cr}_{3} \mathrm{C}_{2}-25(\mathrm{Ni}-20 \mathrm{Cr})$ Coatings," Mater. Res. , vol. 20, no. 4, pp. 994-1002, 2017.

[21] Shabana, M. M. M. Sarcar, K. N. S. Suman, and S. Kamaluddin, "Tribological and Corrosion Behavior of HVOF Sprayed WC-Co, NiCrBSi and $\mathrm{Cr}_{3} \mathrm{C}_{2}-\mathrm{NiCr}$ Coatings and analysis using Design of Experiments," Mater. Today Proc. , vol. 2, no. 4-5, pp. 2654-2665, 2015.

[22] G. Bolelli, L.-M. Berger, T. Börner, H. Koivuluoto, V. Matikainen, L. Lusvarghi, C. Lyphout, N. Markocsan, P. Nylén, P. Sassatelli, R. Trache, and P. Vuoristo, "Sliding and abrasive wear behaviour of HVOFand HVAF-sprayed $\mathrm{Cr}_{3} \mathrm{C}_{2}-\mathrm{NiCr}$ hardmetal coatings," Wear , vol. 358-359, pp. 32-50, 2016.

[23] R. C. Souza, H. J. C. Voorwald, M. O. H. Cioffi, "Fatigue strength of $\mathrm{HVOF}$ sprayed $\mathrm{Cr}_{3} \mathrm{C}_{2}-25 \mathrm{NiCr}$ and WC-10Ni on AISI 4340 steel", Surface Coatings Technology, vol. 203, pp. 191 - 198, 2008.

[24] B. H. B. Kuffner, G. Silva, C. A. Rodrigues, and G. Rodrigues, "Study of the AISI 52100 Steel Reuse Through the Powder Metallurgy Route Using High Energy Ball Milling," Mater. Res. , 2017.

[25] M. C. Brupbacher, D. Zhang, W. M. Buchta, M. L. Graybeal, Y. R. Rhim, D. C. Nagle, and J. B. Spicer, "Synthesis and Characterization of Binder-Free $\mathrm{Cr}_{3} \mathrm{C}_{2}$ Coatings on Nickel-Based Alloys for Molten Fluoride Salt Corrosion Resistance," J. Nucl. Mater. , vol. 461, pp. 215-220, 2015.

[26] L. Janka, L. M. Berger, J. Norpoth, R. Trache, S. Thiele, C. Tomastik, V. Matikainen, and P. Vuoristo, "Improving the high temperature abrasion resistance of thermally sprayed $\mathrm{Cr}_{3} \mathrm{C}_{2}-\mathrm{NiCr}$ coatings by WC addition," Surf. Coatings Technol., vol. 337, no. January, pp. 296-305, 2018. 
[27] S. T. Praxair, "Catalog of Powder Solutions", Praxair Surface Technologies, 2014.

[28] A. C. Karaoglanli, M. Oge, K. M. Doleker, and M. Hotamis, "Comparison of tribological properties of HVOF sprayed coatings with different composition," Surf. Coatings Technol., vol. 318, pp. 299-308, 2017.

[29] M. Amin, L. Daoxin, Z. Xiaohua, H. Guangyu, L. Dan, L. Chengsong, X. Xingchen, "The fretting fatigue performance of Ti-6Al-4V alloy influenced by microstructure of CuNiIn coating prepared via thermal spraying", Tribology International, 145, 106156, 2020.

[30] S. Singh, H. S. Sidhu, and B. S. Sidhu, "Characterisation and Corrosion-Erosion Behaviour of Carbide based Thermal Spray Coatings," J. Miner. Mater. Charact. Eng., vol. 11, no. 6, pp. 569-586, 2012.

Table 1. HVOF spraying parameters of the $\mathrm{Cr}_{3} \mathrm{C}_{2}-25 \mathrm{NiCr}$ coating.

\begin{tabular}{ll}
\hline Flow rate of propane $\left(\mathrm{GPH}^{\mathrm{a}}\right)$ & 5,1 \\
Flow rate of oxygen $\left(\mathrm{SCFH}^{\mathrm{b}}\right)$ & 2054 \\
Feeding rate $(\mathrm{g} / \mathrm{min})$ & 40 \\
Spray distance $(\mathrm{mm})$ & 220 \\
Number of passes & 01 \\
Spray angle $\left(^{\circ}\right)$ & 90 \\
\hline a $1 \mathrm{GPH}=3,785 \mathrm{~L} / \mathrm{h}$ & \\
b $1 \mathrm{SCFH}=0,472 \mathrm{~L} / \mathrm{min}$ &
\end{tabular}

\begin{tabular}{|cccc|}
\hline Eeature & \multicolumn{3}{c|}{ Coating } \\
\cline { 2 - 4 } & Nano & Micro & NM \\
Hardness & $1.166 \mathrm{HK}$ & $1.081 \mathrm{HK}$ & $1.177 \mathrm{HK}$ \\
Thickness & $42 \mathrm{\mu m}$ & $40 \mathrm{\mu m}$ & $50 \mathrm{\mu m}$ \\
Porosity & $(9 \mathrm{\mu m})$ & $(8 \mathrm{\mu m})$ & $(5 \mathrm{\mu m})$ \\
Roughness & $1,410 \mathrm{\mu m}$ & Below $2 \%$ & \\
\hline
\end{tabular}



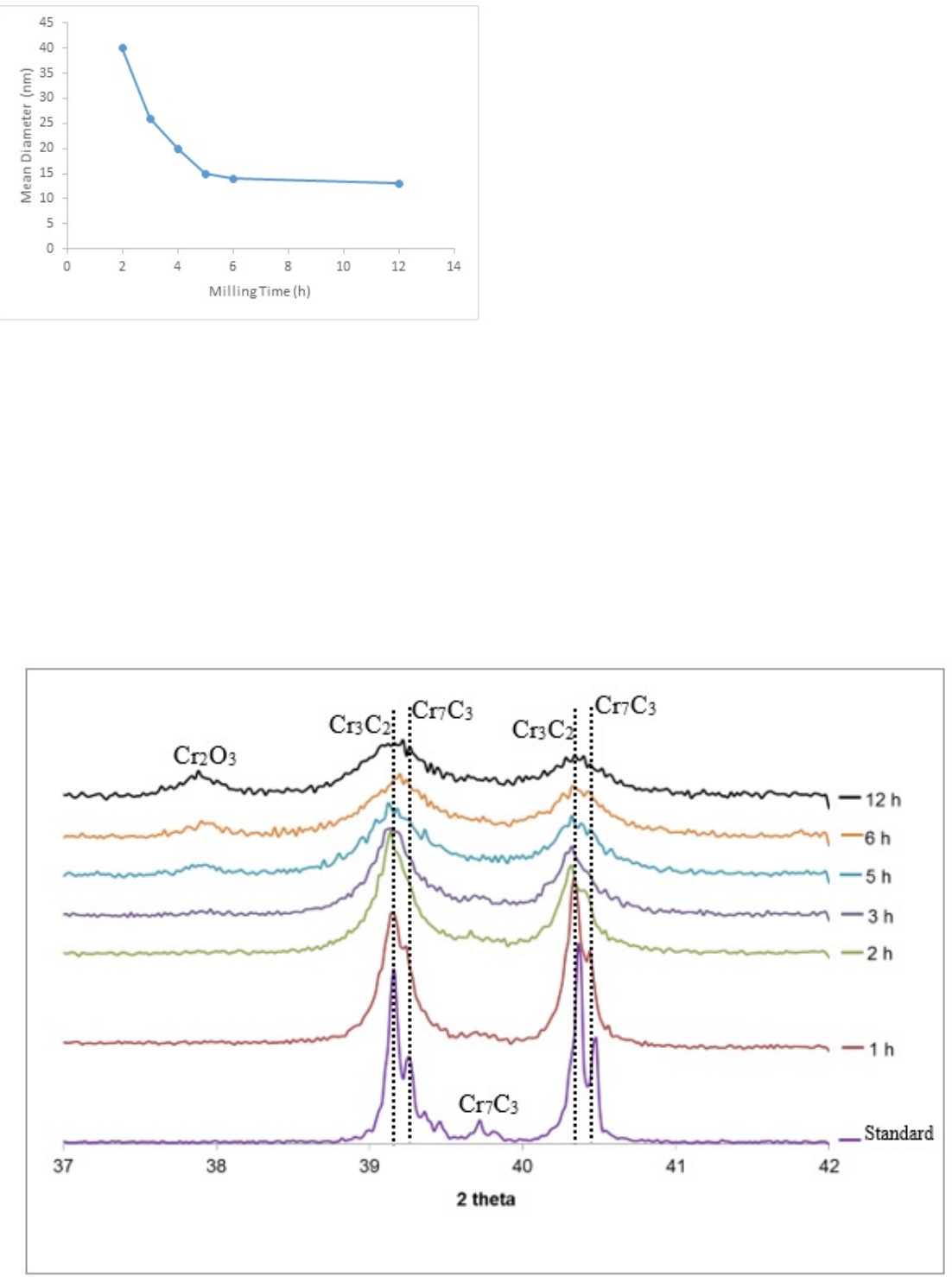


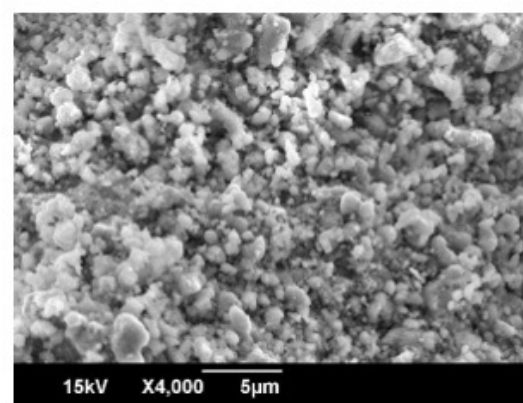

(a)

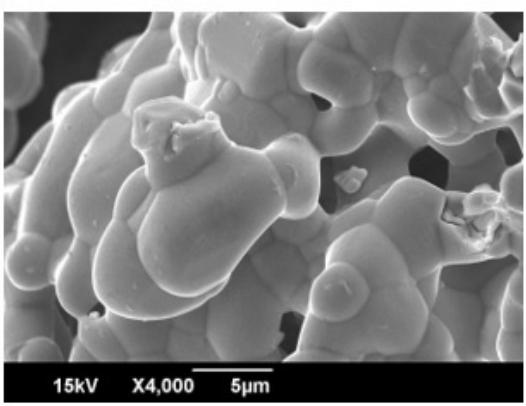

(b)

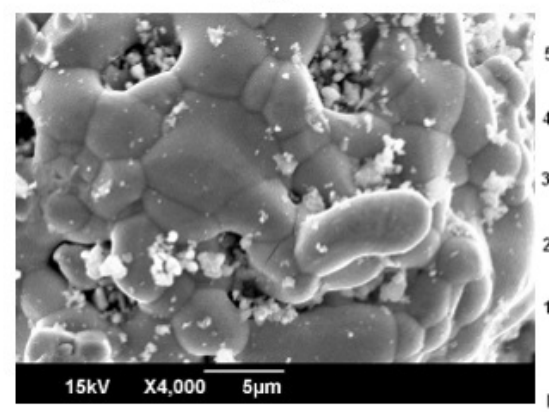

(c)

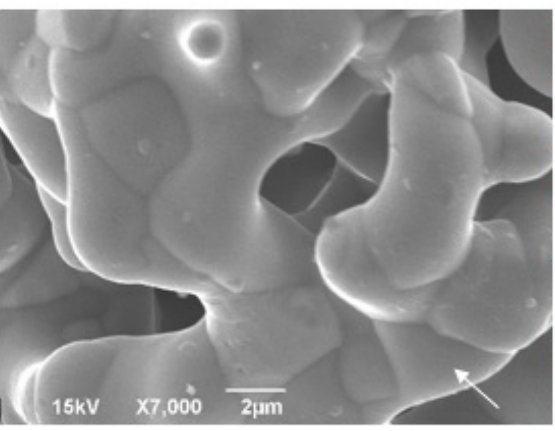

(a)

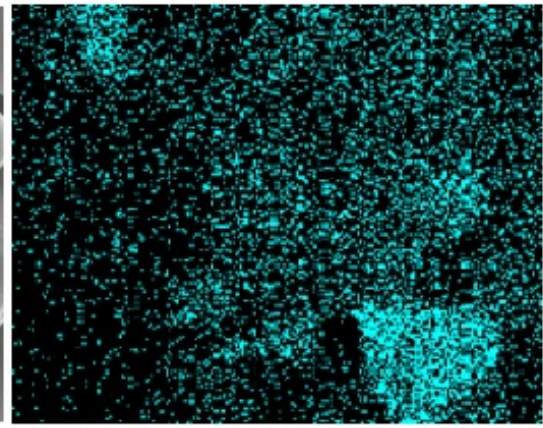

(b)

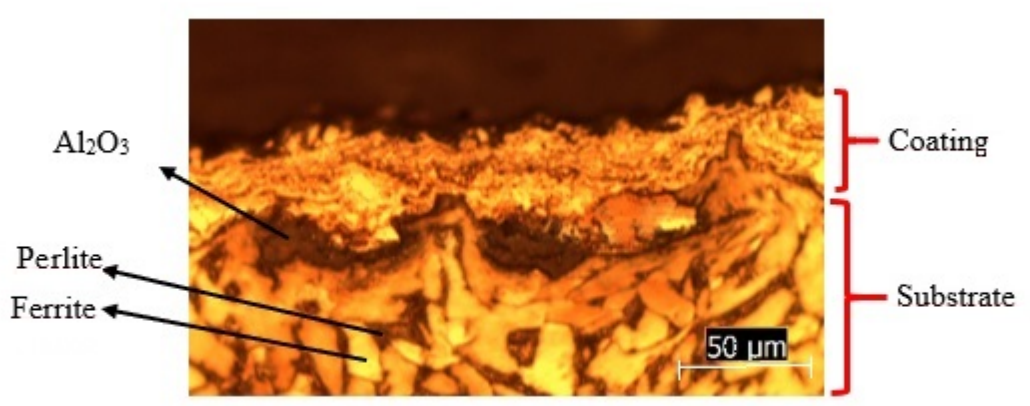




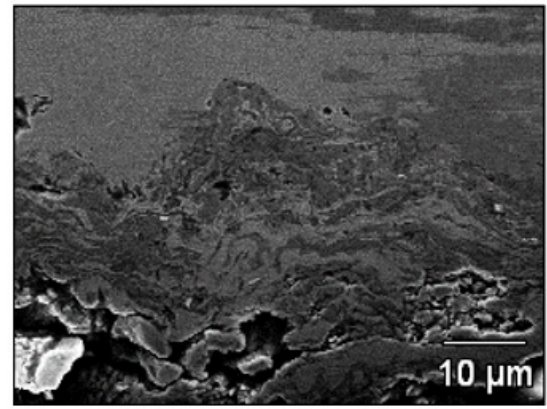

(a)

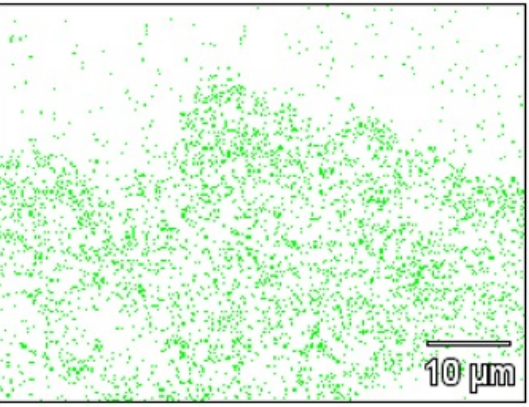

(b)

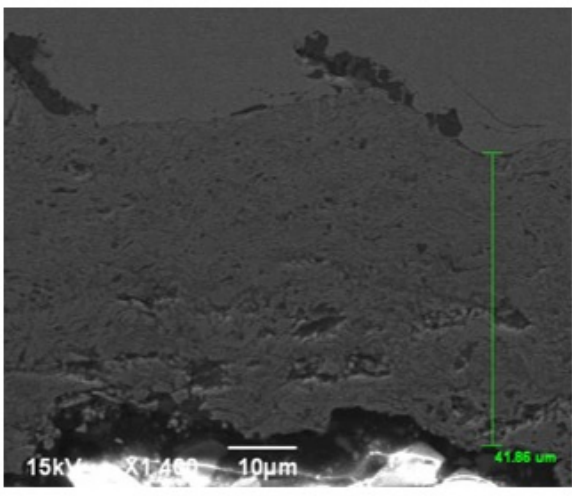

(a)

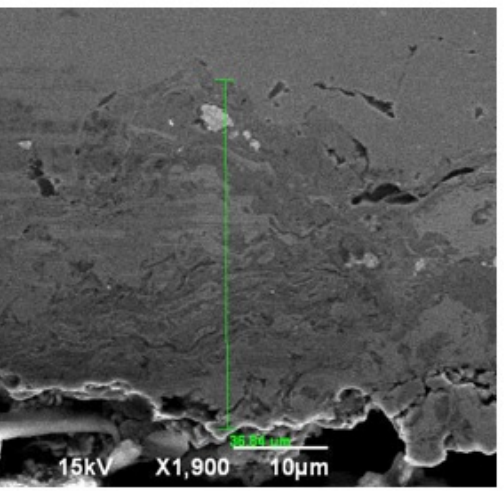

(b)

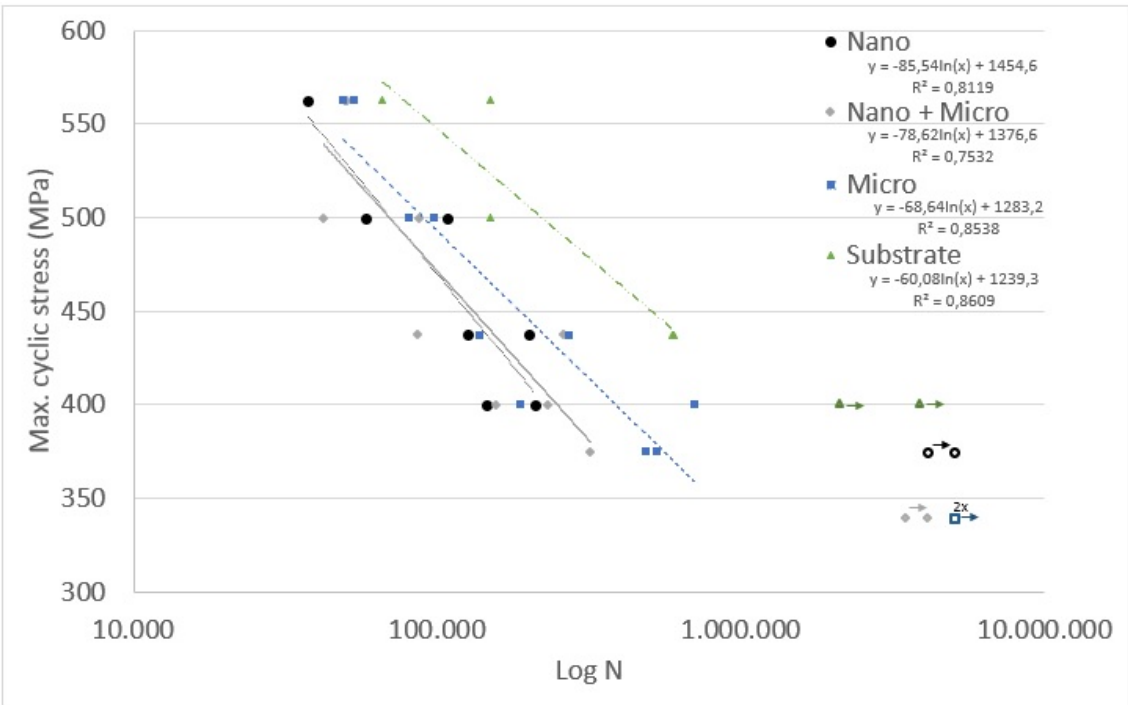




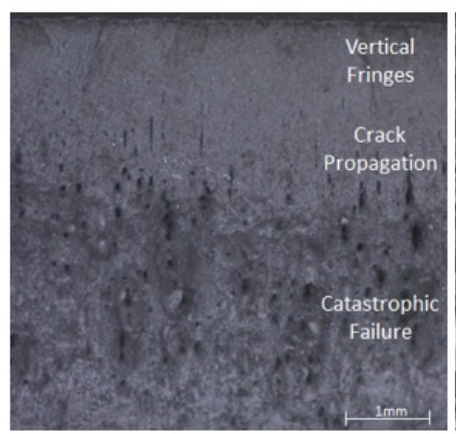

(a)

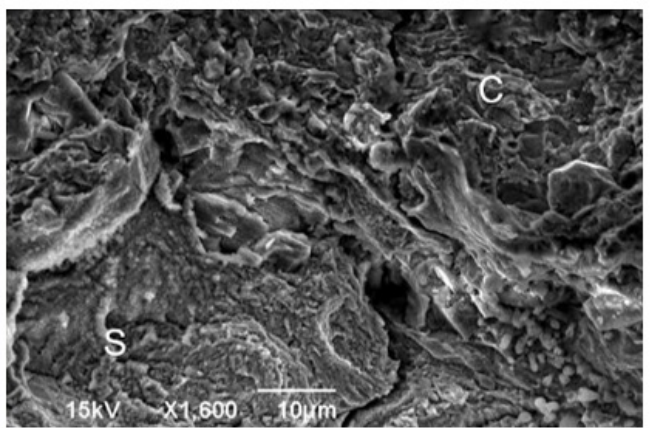

(b)

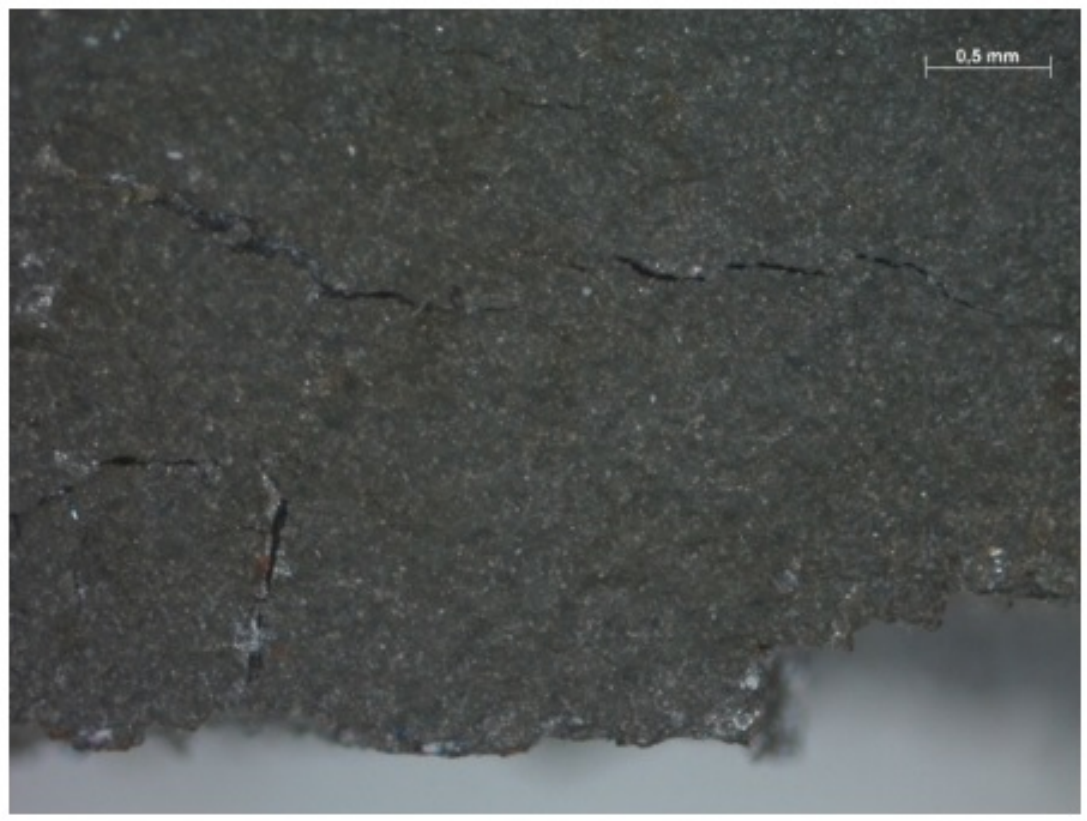

